\title{
Patterns and Trends in Cancer Screening in the United States
}

\author{
Ingrid J. Hall, Ph.D, MPH${ }^{1}$; Florence K.L. Tangka, $\mathrm{PhD}^{1}$; Susan A. Sabatino, MD, MPH${ }^{1}$; \\ Trevor D. Thompson, BS ${ }^{1}$; Barry I. Graubard, Ph.D ${ }^{2}$; Nancy Breen, PhD $^{3}$
}

Accessible Version: www.cdc.gov/pcd/issues/2018/17_0465.htm

Suggested citation for this article: Hall IJ, Tangka FK, Sabatino SA, Thompson TD, Graubard BI, Breen N. Patterns and Trends in Cancer Screening in the United States. Prev Chronic Dis 2018;15:170465. DOI: https://doi.org/10.5888/pcd15.170465.

\section{PEER REVIEWED}

\section{Abstract}

\section{Introduction}

We examined the prevalence of cancer screening reported in 2015 among US adults, adjusted for important sociodemographic and access-to-care variables. By using data from the National Health Interview Survey (NHIS) for 2000 through 2015, we examined trends in prevalence of cancer screening that adhered to US Preventive Services Task Force screening recommendations in order to monitor screening progress among traditionally underserved population subgroups.

\section{Methods}

We analyzed NHIS data from surveys from 2000 through 2015 to estimate prevalence and trends in use of recommended screening tests for breast, cervical, colorectal, and prostate cancers. We used logistic regression and report predictive margins for population subgroups adjusted for various socioeconomic and demographic variables.

\section{Results}

Colorectal cancer screening was the only test that increased during the study period. We found disparities in prevalence of test use among subgroups for all tests examined. Factors that reduced the use of screening tests included no contact with a doctor in the past year, no usual source of health care, and no insurance coverage.

\section{Conclusion}

Understanding use of cancer screening tests among different population subgroups is vital for planning public health interventions with potential to increase screening uptake and reduce disparities in cancer morbidity and mortality. Overarching goals of Healthy People 2020 are to "achieve health equity, eliminate disparities, and improve the health of all groups." Adjusted findings for 2015, compared with previous years, show persistent screening disparities, particularly among the uninsured, and progress for colorectal cancer screening only.

\section{Introduction}

Breast, cervical, colorectal, and prostate cancers cause significant health burdens in the United States. In 2013, these cancers accounted for nearly $40 \%$ of all new cancer diagnoses and about $20 \%$ of cancer deaths (1). Screening is a primary tool for early detection and reduction in deaths from cancer. Examining screening disparities - differences in receipt of screening among population subgroups - over time offers the opportunity to monitor cancer screening successes and advancement toward Healthy People 2020 goals (2).

Healthy People 2020 objectives for use of cancer screening tests include increasing the proportion of women aged 21 to 65 screened for cervical cancer, women aged 50 to 74 screened for breast cancer, and men and women aged 50 to 75 screened for colorectal cancer (2). Healthy People 2020 objectives also include reducing prostate cancer deaths (2). Routine prostate-specific antigen (PSA) testing was not recommended (3) at the time of this analysis; however, test use was common (4).

The National Health Interview Survey (NHIS) has been used for more than 30 years to measure the nation's progress toward meeting Healthy People objectives for cancer screening (2). This article examines the sex-specific prevalence of use of screening tests for cervical, breast, colorectal, and prostate cancers reported by adults in NHIS 2015. Adjusting for sociodemographic characteristics and access to care factors, we assessed differences in screen- 
ing among underserved groups. We examined screening trends from NHIS for 2000, 2003, 2005, 2008, 2010, 2013, and 2015, testing for possible interactions to assess whether use of cancer screening tests in the United States changed overall and for subgroups over those time periods. We assessed progress toward reducing screening disparities, which should aid in decreasing the overall burden of cancer in the United States. This information can be used to assess the persistent unmet needs of underserved groups and to set priorities for interventions to reduce disparities.

\section{Methods}

\section{National Health Interview Survey}

NHIS (www.cdc.gov/nchs/nhis/index.htm), a nationally representative cross-sectional sample of the civilian, noninstitutionalized, US population, is the principal source of information on the health of the nation. The survey excludes residents of long-term care facilities, people on active duty with the Armed Forces (their dependents are included), people incarcerated in the prison system, and US citizens living in foreign countries. NHIS collects sociodemographic and health information via in-person interviews for each participating household. Interviews are conducted by US Census Bureau. The NHIS annual questionnaire includes periodic supplements that cover one or more sets of questions on specific health topics, including cancer screening.

NHIS Cancer Control Supplements were fielded in 2000, 2003, $2005,2008,2010,2013$, and 2015 . The final sample adult response rates ranged from $55.2 \%$ (2015) to $74.2 \%$ (2003) (5). Respondents were asked questions regarding Papanicolaou (Pap) tests and hysterectomy, mammograms, PSA tests, and endoscopic exams and fecal occult blood tests (FOBT) screening for colorectal cancer. For each type of cancer screening, respondents who reported having a test were asked when they had the most recent test.

We used NHIS 2015 data to estimate prevalence of cancer screening. Our definitions of recent screening are consistent with US Preventive Services Task Force (USPSTF) recommendations in effect in 2015. We defined recent breast cancer screening as having received a mammogram within 2 years, recent cervical cancer screening as having a Pap test within 3 years (among women without hysterectomy), and recent colorectal cancer screening as either FOBT within the past year, or flexible sigmoidoscopy within 5 years and FOBT within 3 years, or colonoscopy within 10 years. We used NHIS data from the 2000 through 2015 cycles to describe trends in breast, cervical, and colorectal cancer screening. We examined routine PSA testing in the past year among men aged 50 or older to examine change in use following the 2012 USPSTF guideline revision that recommended against routine screening using PSA (3).

\section{Statistical analysis}

We calculated the proportion of respondents who reported receiving a recent screening test for each type of cancer after adjustment for covariates. We used multivariable logistic regression models to estimate the adjusted association between sociodemographic and access-to-care factors for each type of screening. Independent variables were age, race/ethnicity, education, annual income as a percentage of the federal poverty level, length of US residency, health insurance status and type, having a usual source of care, and consulting a doctor in the past 12 months. Among women, we included consulting a gynecologist in the past 12 months. From logistic regression results, we estimated predictive margins, which are adjusted proportions of screened individuals (6). The predictive margin is computed for a specific group (eg, type of health insurance) as the sample weighted average of the predicted responses from the logistic regression model, assigning each individual in the sample to that group membership while keeping all other covariates unchanged.

Using combined data from all NHIS years, we used multivariable logistic regression models to assess trends over time. Survey year was included as an independent variable, adjusting for the covariates described above. We assessed interactions between survey year and usual source of care or insurance type by including the appropriate product terms in the logistic regression models. We dropped nonsignificant interactions from the final model by using backward elimination (setting 2 -sided $\alpha=0.05$ ). We present figures depicting the time trends as predictive margins. Statistical testing was based on the Wald $F$ statistic for jointly testing that all regression coefficients for a given covariate were equal to zero. We used $95 \%$ confidence intervals (CIs) around the predictive margins to allow for informal pairwise comparisons, although examining overlap between CIs to determine significance is a conservative method. The National Center for Health Statistics imputed missing income data by using multiple imputation. All analyses were performed by using SAS version 9.3 (SAS Institute Inc) and SUDAAN version 11.0.1 (RTI International) to account for the complex sampling design and to allow for sample weighted estimation. All hypothesis tests were considered significant if the 2 -sided $P$ value unadjusted for multiple comparisons was less than .05 .

\footnotetext{
The opinions expressed by authors contributing to this journal do not necessarily reflect the opinions of the U.S. Department of Health and Human Services, the Public Health Service, the Centers for Disease Control and Prevention, or the authors' affiliated institutions.
} 


\section{Results}

In 2015, most women reported having recent screening for cervical, breast, and colorectal cancer (Table 1). However, estimates for all tests, for both women and men, fell short of Healthy People 2020 targets (Figure 1).
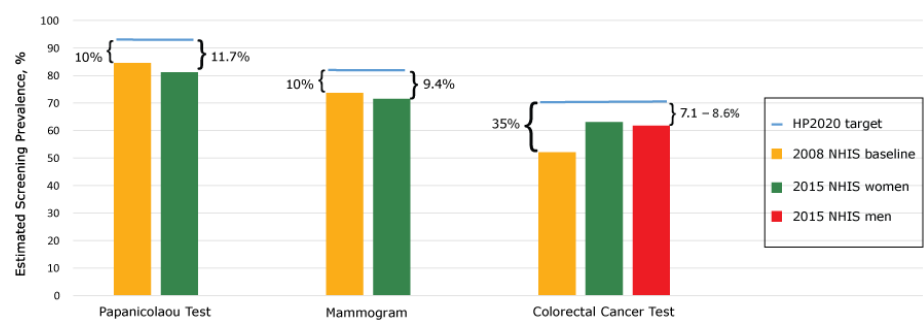

Figure 1. Progress toward meeting Healthy People 2020 cancer screening targets (2), National Health Interview Survey (NHIS) 2008 and 2015 estimates of cancer screening test use based on US Preventive Services Task Force recommendations: Papanicolaou test among women aged 21 to 65 in past 3 years, mammogram among women 50 to 74 within past 2 years, colorectal cancer tests among adults aged 50 to 75 years (fecal occult blood test [FOBT] within past year or flexible sigmoidoscopy past within 5 years and FOBT within past 3 years or colonoscopy within past 10 years). Healthy People 2020 targets represent improvements over 2008 baseline age-adjusted screening levels of $10 \%$ for Papanicolaou test, 10\% for mammography, and 35\% for colorectal cancer testing. Brackets indicate gap between NHIS 2015 reported screening and Healthy People 2020 targets. Abbreviation: NA, not applicable.

\section{Papanicolaou test}

Among women aged 21 to $65,81.3 \%$ (95\% CI, 80.3-82.3) reported having a recent Pap test (Table 1). Reporting a recent Pap test was least likely among women aged 21 to 30 (predictive margin [PM], 78.5; 95\% CI, 76.2-80.6) or 51 to 65 (PM, 80.5; 95\% CI, 78.8-82.1) and among women with less than a high school education (PM, 78.1; 95\% CI, 74.8-81.1), women with no usual source of care (PM, 77.2; 95\% CI, 74.4-79.7), women who were uninsured (PM, 78.0; 95\% CI, 75.2-80.5) or had public insurance only (PM, 79.1, 95\% CI, 76.6-81.3), non-Hispanic Asian women (PM, 77.0; 95\% CI, 72.7-80.8), and women who were US residents for less than 10 years (PM, 71.3; 95\% CI, 65.4-76.6). Women who had not visited a doctor (PM, 76.5; 95\% CI 74.6-78.2) or obstetrician/gynecologist (OB/GYN) (PM, 69.9; 95\% CI, 68.3-71.5) in the past 12 months were least likely to report a recent Pap test.

\section{Mammography}

Among women aged 50 to $74,71.7 \%$ (95\% CI, 70.2-73.1) reported a recent mammogram (Table 1$)$. Reporting a recent mammogram was least likely among women aged 50 to 64 (PM, 70.5; 95\% CI, 68.7-72.3), women with annual incomes less than 139\% of the federal poverty level (PM, 67.1\%; 95\% CI, 63.2-70.8), wo- men without a usual source of care (PM, 53.3; 95\% CI, 45.8-60.7), uninsured women (PM, 54.4; 95\% CI, 47.5-61.2) or publicly insured (PM, 68.1; 95\% CI, 64.7-71.2), and non-Hispanic Asian women (PM, 65.0; 95\% CI, 57.6-71.7) and non-Hispanic white women (PM, 70.0; 95\% CI, 68.0-71.9). Women without recent consults with a doctor (PM, 61.0; 95\% CI, 57.7-64.2) or OB/ GYN (PM, 65.1; 95\% CI, 63.1-67.1) were also less likely to report a recent mammogram.

\section{Colorectal cancer screening}

Among women aged 50 to $75,63.4 \%$ (95\% CI, 61.7-65.0) reported a recent colorectal cancer screening test (Table 2). Reporting a recent screening test was least likely among women aged 50 to 64 (PM, 60.6; 95\% CI, 58.3-62.8), women with less than a high school education (PM, 58.2; 95\% CI, 53.6-62.7), women with an annual income less than $139 \%$ of the federal poverty level (PM, 55.3; 95\% CI, 51.2-59.2), women without a usual source of health care (PM, 45.9, 95\% CI, 38.9-53.1), uninsured women (PM, 45.4; 95\% CI, 37.9-53.2), non-Hispanic Asian women (PM, 54.7; 95\% CI, 47.1-62.1), and women who had not consulted a doctor in the past year (PM, 49.1; 95\% CI, 45.2-53.1) or an OB/GYN in the past year (PM, 60.7; 95\% CI, 58.7-62.5).

Among men aged 50 to $75,61.9 \%$ (95\% CI, 60.0-63.7) reported having recent colorectal cancer screening (Table 3). Reporting recent screening was lowest among men aged 50 to 64 (PM, 57.4; 95\% CI, 55.0-59.7), men with less than a high school education (PM, 53.9; 95\% CI, 48.4-59.3), men with an annual income less than $139 \%$ of the federal poverty level (PM, 55.2; 95\% CI, 50.7-59.7), men without a usual source of health care (PM, 42.2; 95\% CI, 35.5-49.1), uninsured men (PM, 49.0; 95\% CI, 40.8-57.2), and men who had not consulted a doctor in the past 12 months (PM, 47.8; 95\% CI, 44.2-51.5).

\section{Prostate-specific antigen test}

Among men aged 50 years or older, 35.8\% (95\% CI, 34.2-37.4) reported having a PSA test in the past year (Table 3 ). Reporting a recent PSA test was lowest among men aged 50 to 64 years (PM, 30.3 ; 95\% CI, 28.3-32.4), men with less than a high school education (PM, 26.9; 95\% CI, 22.8-31.3), men with annual income less than $139 \%$ of the federal poverty level (PM, 30.8; 95\% CI, 26.6-35.4), men with no usual source of health care (PM, 20.2; 95\% CI, 13.7-28.6), uninsured men (PM, 26.0; 95\% CI, 17.8-36.2), non-Hispanic Asian men (PM, 16.8; 95\% CI, 11.6-23.8), and men who had not consulted a doctor in the past 12 months (PM, 18.3; 95\% CI, 15.3-21.8).

The opinions expressed by authors contributing to this journal do not necessarily reflect the opinions of the U.S. Department of Health and Human Services, the Public Health Service, the Centers for Disease Control and Prevention, or the authors' affiliated institutions. 


\section{Temporal trends in use of cancer screening tests, 2000-2015}

We assessed trends in recent cancer screening test use based on data from the 2000, 2003, 2005, 2008, 2010, 2013, and 2015 NHIS cycles (Figure 2).
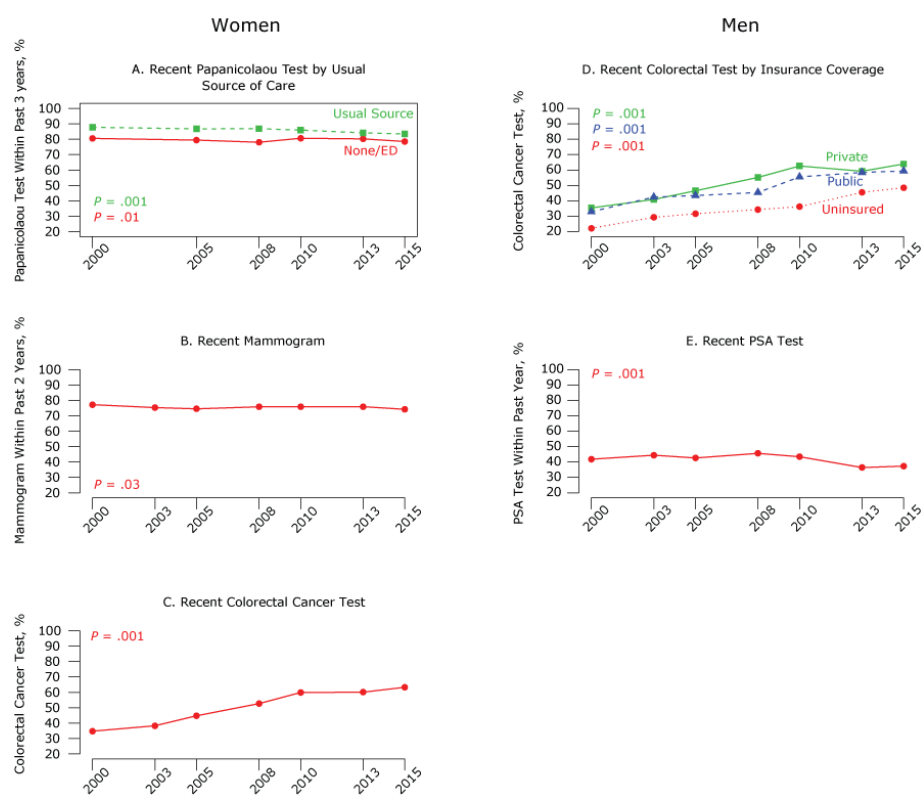

Figure 2. Trends in use of cancer screening tests among women and men, National Health Interview Survey, 2000-2015 (www.cdc.gov/nchs/nhis/index.htm). A. Prevalence of having a Papanicolaou test within past 3 years among women aged 20 to 65. B. Prevalence of having a mammogram among women aged 50 to 74 within past 2 years. C. Prevalence of having a recent colorectal cancer test among women aged 50 to 75 (for colorectal cancer tests, recent is defined as having a fecal occult blood test [FOBT] in the past year, flexible sigmoidoscopy in past 5 years with FOBT in past 3 years, or colonoscopy in past 10 years). D. Prevalence of having a recent colorectal cancer test, by insurance coverage, among men aged 50 to 75 . E. Prevalence of having a PSA test among men aged 50 and older. Estimates were adjusted for age, education, poverty, usual source of care, type of health insurance, race/ethnicity, length of US residency, physician visit in the past year, and among women, OB/GYN visit in the past year. Abbreviations: ED, emergency department; PSA, prostate-specific antigen.

Pap test use declined significantly by $4.3 \%$ from 2000 to 2015 among women with a usual source of care (Figure 2A). No significant change in use was seen among women with no usual source of care. Adjusted mammography rates declined significantly by $3.0 \%$ from 2000 to 2015 , although rates remained relatively high throughout the 2000-2015 period (Figure 2B). No interactions between survey year and usual source of care or insurance type were significant for mammography use. Colorectal cancer screening rates among women increased significantly from 2000 to 2010 , by $25.1 \%$. The rate remained stable from 2010 to 2013 , then increased slightly in 2015 for an overall increase of 28.5\% (Figure $2 \mathrm{C}$ ). No interactions between sociodemographic characteristics, access to care, and recent colorectal cancer tests were significant among women.

Among men, colorectal cancer screening use increased significantly for all men and over time among all insurance groups, but varied by insurance type (Figure 2, D). From 2000 through 2010, the increase was larger among men with private insurance $(27.2 \%)$ than other insurance groups. The rate then declined in 2013 before increasing again in 2015 for an overall increase of $28.5 \%$. The increases among men with public insurance $(26.5 \%)$ and among the uninsured $(26.3 \%)$ were more linear during the period. Use of an annual PSA test declined significantly (9.2\%) from 2008 through 2013 but remained stable from 2013 through 2015, dropping $4.5 \%$ overall (Figure 2E). No significant interactions between sociodemographic characteristics or access to care and having a recent PSA test were observed.

\section{Discussion}

The 2015 NHIS findings show that use of cancer screening tests for cervical, breast, and colorectal cancer remained below Healthy People 2020 targets. Significant variation in test use by sociodemographic characteristics and access to care factors remained after adjustment. For all tests studied, the lowest screening rates were generally associated with having no usual source of care, no insurance, not having seen a physician in the past 12 months, and identifying as non-Hispanic Asian. Younger age, lower income, and fewer years of education were also consistently associated with lower prevalence of screening for both men and women. Examination of trends adjusted for these factors showed a persistent screening disparity over time for those uninsured or with no usual source of care. Patterns of disparities in screening test use found among population subgroups in 2015 were consistent with those found in previous cycles of NHIS (7-9). A striking exception was that non-Hispanic white women were less likely than non-Hispanic black women or Hispanic women to obtain Pap tests or mammograms in 2015.

Only use of colorectal cancer screening increased in 2015 (10). Although rates improved for most groups examined, screening for colorectal cancer was lowest among uninsured women and men (women, 45\%; men, 49\%), those with no usual source of care (women, 46\%; men, 42\%), those with no doctor consult in the past 12 months (women, 49\%; men, 48\%), and non-Hispanic Asians (women, 55\%; men, 51\%). Colorectal cancer screening is effective and can prevent cancer; however, even in 2015, when rates for Pap tests and mammography were $80 \%$ and $70 \%$, respectively, rates for colorectal cancer screening were just above $60 \%$. Focused

The opinions expressed by authors contributing to this journal do not necessarily reflect the opinions of the U.S. Department of Health and Human Services, the Public Health Service, the Centers for Disease Control and Prevention, or the authors' affiliated institutions. 
public health efforts to promote colorectal cancer screening may have helped increase rates over the past 10 years. However, sustained efforts will be necessary to increase awareness of the need for screening, continued expansion of insurance coverage, and use of electronic medical records with automatic reminders to patients and physicians (11) for further increases in test use, particularly among those subgroups with the lowest use.

Pap test and mammography rates showed slight declines in use from 2000 to 2015, and overall measures remained below national targets, especially for specific subgroups of women. Though Pap test screening exceeded $80 \%$, and mammography exceeded $70 \%$, test rates were lower than the Healthy People 2020 targets of $93 \%$ for Pap tests and $81 \%$ for mammography $(2,9)$. In 2017, Watson and colleagues estimated that in 2015, 14 million women aged 21 to 65 had not had a Pap test in the past 3 years (12). To reverse the downward trend and improve outreach to those rarely or never screened, educational and promotional interventions or information dissemination efforts will be needed, and accurate monitoring will be important. Enhanced efforts are needed to increase screening among underserved groups.

The prevalence of use of the PSA test dropped 5 percentage points, from $42.6 \%$ in 2005 to $37.3 \%$ in 2015 , extending earlier trends documenting reduction in test use. In 2012, USPSTF recommended against routine PSA testing and since there has been a drop in the test being offered by physicians and used by patients $(13,14)$ consistent with our findings. In 2015, Drazer and colleagues reported the largest decreases were observed among white men and men aged 50 and older (13); however, screening still occurred in $36 \%$ of men. Approximately one-third of men older than 75 with a life expectancy of less than 10 years were screened in 2013, although screening is never recommended for such patients. A 2017 update to the 2012 USPSTF PSA screening recommendation (15) recommends that men aged 55 to 69 years discuss the potential benefits and harms of PSA screening with their clinician and incorporate their values and preferences in the screening decision. The 2017 update also recommends men aged 70 and older should not be screened, and men at higher risk of prostate cancer, such as African American men or those with a family history, should consult their clinician about the appropriateness of considering screening before age 55 . Therefore, it will be important to continue to monitor test use to determine if prevalence of testing rises following the 2017 update.

The cancer screening objectives for Healthy People 2020 provide targets for monitoring cancer incidence, mortality, and survival. Our analysis of the 2015 NHIS showed that halfway through the Healthy People 2020 decade, estimates for use of cervical, breast, and colorectal cancer screening tests are well below Healthy People 2020 targets. An estimated 24.4 million people would need to be screened in the United States to achieve the National Colorectal Cancer Roundtable target of screening $80 \%$ of age-appropriate individuals by 2018 (16), including 3.9 million people expected to reach screening age from 2015 through 2018.

One approach to improving screening use across all subgroups would be for physicians to recommend screening to all age-appropriate patients (17), including traditionally underserved groups (low-income, uninsured, low acculturation or assimilation, Hispanic, and non-Hispanic Asian) $(18,19)$. Although having insurance coverage does not ensure doctor visits, universal health insurance coverage and universal access to a usual source of health care would likely increase physician access to all groups to encourage screening. Although it would be optimal for physicians to recommend screening to less acculturated and uninsured Hispanics and Asians and in their own languages $(20,21)$, studies suggest that physician enthusiasm and outreach with tailored or innovative strategies to educate and inform (22) may increase knowledge and intention to screen among underserved groups, such as Hispanics, Asians, the uninsured, and the less educated. Culturally tailored strategies may be particularly effective for Asians disproportionately affected by discordance in patient-provider language and gender (provider and patient being of different genders) $(22,23)$. More research and evaluation of public health campaigns designed to increase screening among underserved groups are needed.

Evidence-based, multicomponent interventions have potential to substantially increase screening rates among population groups with low screening rates $(24,25)$. Efforts that result in better continuity and coordination of care, such as community-based patient navigation programs, may be particularly useful. Care coordination is a key strategy with potential to improve health care system effectiveness, safety, and efficiency. Well-designed, targeted coordination efforts can improve patient, provider, and payer outcomes (26). The Community Preventive Services Task Force findings suggest that multicomponent interventions that increase community demand and access along with increasing provider delivery of services show the greatest screening effects (27). Combined with provision of appropriate follow-up care and treatment, these interventions may improve health for the underserved.

Our study had limitations. Survey data were self-reported and not confirmed by medical record review. Data did not distinguish diagnostic tests from screening and may have overestimated test use for screening purposes. In addition, American Indian, Alaska Native, and Pacific Islander samples were too small to analyze separately and were included in a "non-Hispanic other" group; limiting our knowledge about these subgroups. Monitoring screening among all these groups is essential to determine what allocation of resources and efforts is necessary to increase their screening

The opinions expressed by authors contributing to this journal do not necessarily reflect the opinions of the U.S. Department of Health and Human Services, the Public Health Service, the Centers for Disease Control and Prevention, or the authors' affiliated institutions. 
participation. Lastly, beginning in 2010, NHIS asked separate questions for each type of endoscopy (sigmoidoscopy vs colonoscopy). Before 2010, respondents were asked which endoscopy type was the most recent test. If the most recent test was a sigmoidoscopy that occurred within 10 years but did not meet recommendations, we assumed that the sigmoidoscopy was not preceded by a colonoscopy within 10 years, and that screening was not up to date. Although this may underestimate screening slightly, having a sigmoidoscopy following a recent colonoscopy is likely to be rare.

Given the rate of change between 2000 and 2010, accelerated uptake is needed to reach Healthy People 2020 targets for screening for cervical, breast, and colorectal cancers. Again in 2015, the uninsured and those with no usual source of care were least likely to have received a screening test within recommended timelines. Continued efforts are needed to reduce structural barriers for access to medical care and to increase physician contact to increase the proportion of people counseled and participating in cancer screening, particularly among underserved subgroups. In addition to more consistent physician recommendation, screening promotion efforts for all tests directed at patients need to identify and address barriers among Asians, those without a usual source of care, and the uninsured. Culturally and linguistically appropriate and targeted interventions have been shown to maintain high rates of Pap test and mammography screening and to continue to increase colorectal cancer screening (28-30). Appropriate diagnosis, timely follow-up, and effective treatment will help to make inroads toward reducing overall cancer burden and improving health equity in cancer outcomes for all. Continued monitoring is critical to learn how screening rates compare with Healthy People 2020 targets, and it is important to adjust for sociodemographic factors because of changes in insurance coverage and racial/ethnic composition in the population over time.

\section{Acknowledgments}

All authors participated directly in the conceptualization, execution, or analysis of the study; meaningfully contributed to the article's preparation; and read and approved its contents. The authors declare no potential conflicts of interest. This research did not receive any grant from funding agencies in the public, commercial, or not-for-profit sectors. No copyrighted material, surveys, instruments, or tools were used in the article. Findings and conclusions are those of the authors and do not necessarily represent the official position of the Centers for Disease Control and Prevention, the National Cancer Institute, or the National Institute on Minority Health and Health Disparities.

\section{Author Information}

Corresponding Author: Ingrid J. Hall, PhD, MPH, Centers for Disease Control and Prevention, DCPC, 4770 Buford Highway, NE, Mailstop K-76, Atlanta, GA 30341. Telephone: 770-4883035. Email: iah9@cdc.gov.

Author Affiliations: ${ }^{1}$ Division of Cancer Prevention and Control, National Center for Chronic Disease Prevention and Health Promotion, Centers for Disease Control and Prevention, Atlanta, Georgia. ${ }^{2}$ Division of Cancer Epidemiology and Genetics, National Cancer Institute, Bethesda, Maryland. ${ }^{3}$ Office of Science Policy, Strategic Planning, Assessment, Analyses, Resources, Reporting and Data, National Institute on Minority Health and Health Disparities, Bethesda, Maryland.

\section{References}

1. US Cancer Statistics Working Group. United States Cancer Statistics: 1999-2014. Atlanta (GA): US Department of Health and Human Services, Centers for Disease Control and Prevention and National Cancer Institute; 2017. www.cdc.gov/ uscs. Accessed September 25, 2017.

2. Healthy People 2020. Washington (DC): US Department of Health and Human Services, Office of Disease Prevention and Health Promotion. https://www.healthypeople.gov/2020/ topics-objectives/topic/cancer/objectives. Accessed September 25, 2017.

3. Moyer VA; U.S. Preventive Services Task Force. Screening for prostate cancer: US Preventive Services Task Force recommendation statement. Ann Intern Med 2012; 157(2):120-34.

4. Hutchinson R, Akhtar A, Haridas J, Bhat D, Roehrborn C, Lotan Y. Testing and referral patterns in the years surrounding the US Preventive Services Task Force recommendation against prostate-specific antigen screening. Cancer 2016; 122(24):3785-93.

5. National Center for Health Statistics. NHIS data, questionnaires and related documentation. https:// www.cdc.gov/nchs/nhis/data-questionnairesdocumentation.htm. Accessed September 25, 2017.

6. Korn EL, Graubard BI. Analysis of Health Surveys. New York (NY): John Wiley and Sons, Inc; 1999.

7. Sabatino SA, White MC, Thompson TD, Klabunde CN; Centers for Disease Control and Prevention (CDC). Cancer screening test use - United States, 2013. MMWR Morb Mortal Wkly Rep 2015;64(17):464-8.

The opinions expressed by authors contributing to this journal do not necessarily reflect the opinions of the U.S. Department of Health and Human Services, the Public Health Service, the Centers for Disease Control and Prevention, or the authors' affiliated institutions. 
8. Brown ML, Klabunde CN, Cronin KA, White MC, Richardson LC, McNeel TS. Challenges in meeting Healthy People 2020 objectives for cancer-related preventive services, National Health Interview Survey, 2008 and 2010. Prev Chronic Dis 2014;11:E29.

9. Sauer AG, Siegel RL, Jemal A, Fedewa SA. Updated review of prevalence of major risk factors and use of screening tests for cancer in the United States. Cancer Epidemiol Biomarkers Prev 2017;26(8):1192-208; Epub ahead of print.

10. National Cancer Institute. Cancer Trends Progress Report. National Cancer Institute, NIH, DHHS, Bethesda, (MD): National Cancer Institute; January 2017, https:// progressreport.cancer.gov. Accessed September 25, 2017.

11. Levin TR, Jamieson L, Burley DA, Reyes J, Oehrli M, Caldwell C. Organized colorectal cancer screening in integrated health care systems. Epidemiol Rev 2011; 33(1):101-10.

12. Watson M, Benard V, King J, Crawford A, Saraiya M. National assessment of HPV and Pap tests: changes in cervical cancer screening, National Health Interview Survey. Prev Med 2017;100:243-7.

13. Drazer MW, Huo D, Eggener SE. National prostate cancer screening rates after the 2012 US Preventive Services Task Force recommendation discouraging Prostate-Specific Antigen-based screening. J Clin Oncol 2015;33(22):2416-23.

14. Shoag J, Halpern JA, Lee DJ, Mittal S, Ballman KV, Barbieri $\mathrm{CE}$, et al. Decline in prostate cancer screening by primary care physicians: an analysis of trends in the use of digital rectal examination and prostate specific antigen testing. J Urol 2016; 196(4):1047-52.

15. Grossman DCUS, Curry SJ, Owens DK, Bibbins-Domingo K, Caughey AB, Davidson KW, et al. Preventive Services Task Force. Screening for Prostate Cancer. US Preventive Services Task Force Recommendation Statement. JAMA 2018; 319(18):1901-13.

16. Fedewa SA, Ma J, Sauer AG, Siegel RL, Smith RA, Wender $\mathrm{RC}$, et al. How many individuals will need to be screened to increase colorectal cancer screening prevalence to $80 \%$ by 2018? Cancer 2015;121(23):4258-65.

17. Ramdass P, Petraro P, Via C, Shahrokni A, Nawaz H. Providers role in colonoscopy screening for colorectal cancer. Am J Health Behav 2014;38(2):234-44.

18. May FP, Almario CV, Ponce N, Spiegel BM. Racial minorities are more likely than whites to report lack of provider recommendation for colon cancer screening. Am J Gastroenterol 2015;110(10):1388-94.

19. Miranda-Diaz C, Betancourt E, Ruiz-Candelaria Y, HunterMellado RF. Barriers for compliance to breast, colorectal, and cervical screening cancer tests among Hispanic patients. Int $\mathbf{J}$ Environ Res Public Health 2015;13(1):ijerph13010021.
20. Costas-Muñiz R, Jandorf L, Philip E, Cohen N, Villagra C, Sriphanlop P, et al. Examining the impact of Latino nativity, migration, and acculturation factors on colonoscopy screening. J Community Health 2016;41(5):903-9.

21. Nápoles AM, Santoyo-Olsson J, Stewart AL, Olmstead J, Gregorich SE, Farren G, et al. Physician counseling on colorectal cancer screening and receipt of screening among Latino patients. J Gen Intern Med 2015;30(4):483-9.

22. Chawla N, Breen N, Liu B, Lee R, Kagawa-Singer M. Asian American women in California: a pooled analysis of predictors for breast and cervical cancer screening. Am J Public Health 2015;105(2):e98-109.

23. Thompson CA, Gomez SL, Chan A, Chan JK, McClellan SR, Chung S, et al. Patient and provider characteristics associated with colorectal, breast, and cervical cancer screening among Asian Americans. Cancer Epidemiol Biomarkers Prev 2014; 23(11):2208-17.

24.The Community Guide. Cancer. https:// www.thecommunityguide.org/topic/cancer. Accessed February $25,2018$.

25. Joseph DA, Redwood D, DeGroff A, Butler EL. Use of evidence-based interventions to address disparities in colorectal cancer screening. MMWR Suppl 2016;65(1):21-8.

26. Agency for Healthcare Research and Quality. Care Coordination. https://www.ahrq.gov/professionals/preventionchronic-care/improve/coordination/index.html. Accessed February 20, 2018.

27. The Community Guide. Cancer screening: multicomponent interventions - breast cancer. https:// www.thecommunityguide.org/findings/cancer-screeningmulticomponent-interventions-breast-cancer. Accessed February 26, 2018.

28. Hall IJ, Johnson-Turbes A, Berkowitz Z, Zavahir Y. The African American Women and Mass Media (AAMM) campaign in Georgia: quantifying community response to a CDC pilot campaign. Cancer Causes Control 2015; 26(5):787-94.

29. Byrd TL, Wilson KM, Smith JL, Coronado G, Vernon SW, Fernandez-Esquer ME, et al. AMIGAS: a multicity, multicomponent cervical cancer prevention trial among Mexican American women. Cancer 2013;119(7):1365-72.

30. Nguyen TT, Tsoh JY, Woo K, Stewart SL, Le GM, Burke A, et al. Colorectal cancer screening and Chinese Americans: efficacy of lay health worker outreach and print materials. Am J Prev Med 2017;52(3):e67-76.

The opinions expressed by authors contributing to this journal do not necessarily reflect the opinions of the U.S. Department of Health and Human Services, the Public Health Service, the Centers for Disease Control and Prevention, or the authors' affiliated institutions. 


\section{Tables}

Table 1. Screening for Cervical and Breast Cancer Among Women, by Demographic Characteristics and Access to Care, National Health Interview Survey, United States, 2015

\begin{tabular}{|c|c|c|c|c|c|c|}
\hline \multirow[b]{2}{*}{ Characteristic } & \multicolumn{3}{|c|}{ Cervical Cancer, Papanicolaou Test Within Past 3 years } & \multicolumn{3}{|c|}{ Breast Cancer, Mammogram Within Past 2 years } \\
\hline & No. & Predictive Margin $^{a}(95 \% \mathrm{Cl})$ & $P$ Value & No. & Predictive Margin $^{a}(95 \% \mathrm{Cl})$ & $P$ Value \\
\hline Total & 10,431 & $81.3(80.3-82.3)$ & NA & 6,663 & $71.7(70.2-73.1)$ & $N$ \\
\hline
\end{tabular}

Age group (y)

\begin{tabular}{|l|r|r|}
\hline $21-30$ & 2,558 & $78.5(76.2-80.6)$ \\
\hline $31-40$ & 2,624 & $84.8(83.0-86.5)$ \\
\hline $41-50$ & 2,172 & $82.1(80.1-83.9)$ \\
\hline $50-64$ & $\mathrm{NA}$ & $\mathrm{NA}$ \\
\hline $51-65$ & 3,077 & $80.5(78.8-82.1)$ \\
\hline $65-74$ & $-{ }^{\mathrm{b}}$ & $-{ }^{\mathrm{b}}$ \\
\hline
\end{tabular}

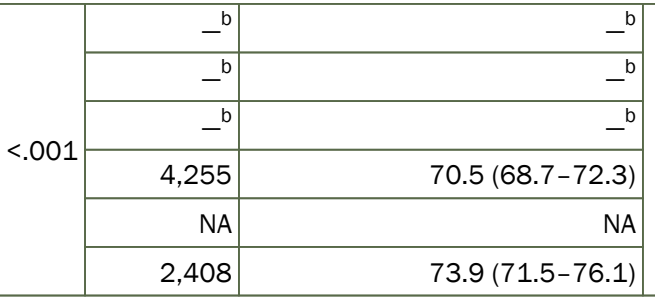

\section{Education}

\begin{tabular}{|c|c|c|c|c|c|}
\hline Less than high school & 1,213 & $78.1(74.8-81.1)$ & \multirow{4}{*}{$<.001$} & 855 & $69.3(64.9-73.4)$ \\
\hline High school graduate & 2,138 & $78.8(76.7-80.9)$ & & 1,687 & $70.4(67.6-73.1)$ \\
\hline Some college or associate degree & 3,426 & $81.4(79.7-83.1)$ & & 2,164 & $70.6(67.9-73.2)$ \\
\hline College graduate & 3,654 & $84.4(82.7-86.0)$ & & 1,957 & $75.0(72.1-77.7)$ \\
\hline
\end{tabular}

Annual income, percentage of federal poverty level

\begin{tabular}{|c|c|c|c|c|c|}
\hline$<139 \%$ & 2,941 & $80.2(78.1-82.1)$ & \multirow{4}{*}{.06} & 1,542 & $67.1(63.2-70.8)$ \\
\hline $139 \%-250 \%$ & 2,066 & 80.1 (78.0-82.0) & & 1,302 & $67.5(63.6-71.2)$ \\
\hline $251 \%-400 \%$ & 1,957 & $80.3(78.0-82.4)$ & & 1,299 & $73.9(70.7-76.8)$ \\
\hline$>400 \%$ & 3,467 & $83.7(81.6-85.6)$ & & 2,520 & $74.6(71.9-77.1)$ \\
\hline
\end{tabular}

Usual source of health care

\begin{tabular}{|l|r|r|r|r|r|}
\hline None or hospital ER & 1,403 & $77.2(74.4-79.7)$ & 388 & $<.001$ & $53.3(45.8-60.7)$ \\
\cline { 1 - 3 } \cline { 1 - 2 } & 9,028 & $82.2(81.1-83.3)$ & $<.001$ \\
\cline { 1 - 3 }
\end{tabular}

Health insurance

\begin{tabular}{|c|c|c|c|c|c|c|}
\hline Private/military & 6,997 & $82.8(81.5-84.0)$ & \multirow{3}{*}{$<.001$} & 4,374 & $74.4(72.3-76.3)$ & \multirow{3}{*}{$<.001$} \\
\hline Public only ${ }^{c}$ & 2,124 & 79.1 (76.6-81.3) & & 1,922 & $68.1(64.7-71.2)$ & \\
\hline Uninsured & 1,310 & $78.0(75.2-80.5)$ & & 367 & $54.4(47.5-61.2)$ & \\
\hline \multicolumn{7}{|l|}{ Race/ethnicity } \\
\hline Hispanic & 2,089 & $83.8(81.4-86.0)$ & \multirow{3}{*}{$<.001$} & 823 & $79.3(74.8-83.2)$ & \multirow{3}{*}{$<.001$} \\
\hline Non-Hispanic white & 6,033 & $80.3(78.8-81.7)$ & & 4,517 & $70.0(68.0-71.9)$ & \\
\hline Non-Hispanic black & 1,544 & $84.5(82.4-86.4)$ & & 971 & $77.1(73.6-80.3)$ & \\
\hline
\end{tabular}

Abbreviations: $\mathrm{Cl}$, confidence interval; NA, not applicable.

${ }^{a}$ Proportions of screened individuals adjusted for all covariates in table. Values are computed for a specific group (eg, type of health insurance) as the sample weighted average of the predicted responses from the logistic regression model, assigning each individual in the sample to that group membership while keeping all other covariates unchanged. The sample totals for this table are crude estimates of the proportion screened in the total population.

${ }^{b}$ Screening is not recommended for this age group.

${ }^{c}$ Medicare and/or Medicaid.

${ }^{\mathrm{d}}$ American Indian, Alaska Native, and Pacific Islander.

\footnotetext{
The opinions expressed by authors contributing to this journal do not necessarily reflect the opinions of the U.S. Department of Health and Human Services, the Public Health Service, the Centers for Disease Control and Prevention, or the authors' affiliated institutions.
} 
(continued)

Table 1. Screening for Cervical and Breast Cancer Among Women, by Demographic Characteristics and Access to Care, National Health Interview Survey, United States, 2015

\begin{tabular}{|c|c|c|c|c|c|c|}
\hline \multirow[b]{2}{*}{ Characteristic } & \multicolumn{3}{|c|}{ Cervical Cancer, Papanicolaou Test Within Past 3 years } & \multicolumn{3}{|c|}{ Breast Cancer, Mammogram Within Past 2 years } \\
\hline & No. & Predictive Margin $^{a}(95 \% \mathrm{Cl})$ & $P$ Value & No. & Predictive Margin $^{a}(95 \% \mathrm{Cl})$ & $P$ Value \\
\hline Non-Hispanic Asian & 649 & $77.0(72.7-80.8)$ & & 294 & $65.0(57.6-71.7)$ & \\
\hline Non-Hispanic other ${ }^{d}$ & 116 & $77.8(66.5-86.1)$ & & 58 & $69.7(50.6-83.8)$ & \\
\hline \multicolumn{7}{|l|}{ Length of US residency } \\
\hline In United States $<10$ years & 458 & $71.3(65.4-76.6)$ & \multirow{3}{*}{$<.001$} & 69 & $69.0(56.3-79.4)$ & \multirow{3}{*}{.87} \\
\hline In United States $\geq 10$ years & 1,759 & $81.1(78.4-83.6)$ & & 957 & $70.9(65.7-75.6)$ & \\
\hline US-born & 8,214 & $81.9(80.7-83.1)$ & & 5,637 & $71.8(70.3-73.4)$ & \\
\hline \multicolumn{7}{|c|}{ Consulted doctor in past 12 months } \\
\hline Yes & 7,103 & $84.1(83.0-85.2)$ & \multirow{2}{*}{$<.001$} & 5,411 & $74.2(72.5-75.8)$ & \multirow{2}{*}{$<.001$} \\
\hline No & 3,328 & $76.5(74.6-78.2)$ & & 1,252 & $61.0(57.7-64.2)$ & \\
\hline \multicolumn{7}{|c|}{ Consulted OB/GYN in past 12 months } \\
\hline Yes & 4,662 & $96.0(95.2-96.7)$ & \multirow{2}{*}{$<.001$} & 1,855 & $86.6(84.2-88.7)$ & \multirow{2}{*}{$<.001$} \\
\hline No & 5,769 & $69.9(68.3-71.5)$ & & 4,808 & $65.1(63.1-67.1)$ & \\
\hline
\end{tabular}

Abbreviations: $\mathrm{Cl}$, confidence interval; NA, not applicable.

${ }^{\text {a }}$ Proportions of screened individuals adjusted for all covariates in table. Values are computed for a specific group (eg, type of health insurance) as the sample weighted average of the predicted responses from the logistic regression model, assigning each individual in the sample to that group membership while keeping all other covariates unchanged. The sample totals for this table are crude estimates of the proportion screened in the total population.

${ }^{\mathrm{b}}$ Screening is not recommended for this age group.

${ }^{c}$ Medicare and/or Medicaid.

${ }^{\mathrm{d}}$ American Indian, Alaska Native, and Pacific Islander. 
Table 2. Screening ${ }^{a}$ for Colorectal Cancer Among Women, by Demographic Characteristics and Access to Care, National Health Interview Survey, United States, 2015

\begin{tabular}{|c|c|c|c|}
\hline Characteristic & No. & Predictive Margin $^{\mathrm{b}}(95 \% \mathrm{Cl})$ & $P$ Value \\
\hline Total & 6,816 & $63.4(61.7-65.0)$ & NA \\
\hline \multicolumn{4}{|l|}{ Age group, $y$} \\
\hline $50-64$ & 4,232 & $60.6(58.3-62.8)$ & \multirow{2}{*}{$<.001$} \\
\hline $65-75$ & 2,584 & $68.8(66.3-71.2)$ & \\
\hline \multicolumn{4}{|l|}{ Education } \\
\hline Less than high school & 885 & $58.2(53.6-62.7)$ & \multirow{4}{*}{.03} \\
\hline High school graduate & 1,748 & $61.5(58.5-64.5)$ & \\
\hline Some college or associate degree & 2,204 & $64.4(61.6-67.1)$ & \\
\hline College graduate & 1,979 & $65.8(62.6-68.9)$ & \\
\hline \multicolumn{4}{|l|}{ Annual income, percentage of poverty level } \\
\hline$<139$ & 1,575 & $55.3(51.2-59.2)$ & \multirow{4}{*}{$<.001$} \\
\hline $139-250$ & 1,350 & $59.6(55.3-63.7)$ & \\
\hline $251-400$ & 1,340 & $64.0(60.5-67.4)$ & \\
\hline$>400$ & 2,551 & $67.9(65.2-70.4)$ & \\
\hline \multicolumn{4}{|l|}{ Usual source of health care } \\
\hline None or hospital emergency department & 394 & $45.9(38.9-53.1)$ & \multirow[t]{2}{*}{$<.001$} \\
\hline Has usual source & 6,422 & $64.2(62.5-65.9)$ & \\
\hline \multicolumn{4}{|l|}{ Health insurance } \\
\hline Private/military & 4,455 & $64.2(62.2-66.2)$ & \multirow{3}{*}{$<.001$} \\
\hline Public only ${ }^{c}$ & 1,990 & $64.0(60.5-67.4)$ & \\
\hline Uninsured & 371 & $45.4(37.9-53.2)$ & \\
\hline \multicolumn{4}{|l|}{ Race/ethnicity } \\
\hline Hispanic & 835 & $59.3(54.1-64.2)$ & \multirow{5}{*}{.05} \\
\hline Non-Hispanic white & 4,631 & $64.5(62.4-66.5)$ & \\
\hline Non-Hispanic black & 989 & $64.8(60.9-68.5)$ & \\
\hline Non-Hispanic Asian & 303 & $54.7(47.1-62.1)$ & \\
\hline Non-Hispanic other ${ }^{d}$ & 58 & $50.3(30.1-70.4)$ & \\
\hline \multicolumn{4}{|l|}{ Length of US residency } \\
\hline$<10$ years & 73 & $55.1(38.8-70.4)$ & \multirow{3}{*}{.41} \\
\hline$\geq 10$ years & 980 & $61.3(56.3-66.1)$ & \\
\hline US-born & 5,763 & $63.8(62.0-65.6)$ & \\
\hline Consulted doctor in past 12 months & & & \\
\hline
\end{tabular}

Abbreviations: $\mathrm{Cl}$, confidence interval; OB/GYN, obstetrician/gynecologist' NA, not applicable.

${ }^{a}$ Fecal occult blood test (FOBT) in the past year, flexible sigmoidoscopy in past 5 years with FOBT in past 3 years, or colonoscopy in past 10 years.

${ }^{\mathrm{b}}$ Proportions of screened individuals adjusted for all covariates in table. Values are computed for a specific group (eg, type of health insurance) as the sample weighted average of the predicted responses from the logistic regression model, assigning each individual in the sample to that group membership while keeping all other covariates unchanged. The sample totals for this table are crude estimates of the proportion screened in the total population.

${ }^{c}$ Medicare and/or Medicaid.

${ }^{d}$ American Indian, Alaska Native, and Pacific Islander. 
(continued)

Table 2. Screening ${ }^{a}$ for Colorectal Cancer Among Women, by Demographic Characteristics and Access to Care, National Health Interview Survey, United States, 2015

\begin{tabular}{|c|c|c|c|}
\hline Characteristic & No. & Predictive Margin $^{\mathrm{b}}$ (95\% Cl) & $P$ Value \\
\hline Yes & 5,542 & $66.5(64.7-68.2)$ & \multirow{2}{*}{$<.001$} \\
\hline No & 1,274 & $49.1(45.2-53.1)$ & \\
\hline \multicolumn{4}{|c|}{ Consulted OB/GYN in past 12 months } \\
\hline Yes & 1,872 & $69.2(66.3-72.0)$ & \multirow{2}{*}{$<.001$} \\
\hline No & 4,944 & $60.7(58.7-62.5)$ & \\
\hline
\end{tabular}

Abbreviations: Cl, confidence interval; OB/GYN, obstetrician/gynecologist' NA, not applicable.

${ }^{\text {a }}$ Fecal occult blood test (FOBT) in the past year, flexible sigmoidoscopy in past 5 years with FOBT in past 3 years, or colonoscopy in past 10 years.

${ }^{b}$ Proportions of screened individuals adjusted for all covariates in table. Values are computed for a specific group (eg, type of health insurance) as the sample weighted average of the predicted responses from the logistic regression model, assigning each individual in the sample to that group membership while keeping all other covariates unchanged. The sample totals for this table are crude estimates of the proportion screened in the total population.

${ }^{\mathrm{C}}$ Medicare and/or Medicaid.

${ }^{\mathrm{d}}$ American Indian, Alaska Native, and Pacific Islander. 
Table 3. Cancer Screening Among Men, by Demographic Characteristics and Access to Care, National Health Interview Survey, United States, 2015

\begin{tabular}{|c|c|c|c|c|c|c|}
\hline \multirow[b]{2}{*}{ Characteristic } & \multicolumn{3}{|c|}{ Colorectal Cancer, Recent Test ${ }^{a}$} & \multicolumn{3}{|c|}{ Prostate Cancer, PSA Test in Past Year } \\
\hline & No. & Predictive Margin $(95 \% \mathrm{Cl})$ & $P$ Value & No. & Predictive Margin $^{\mathrm{b}}(95 \% \mathrm{Cl})$ & $P$ Value \\
\hline Total & 5,679 & $61.9(60.0-63.7)$ & NA & 6,636 & $35.8(34.2-37.4)$ & NA \\
\hline \multicolumn{7}{|l|}{ Age group, $y$} \\
\hline $50-64$ & 3,606 & $57.4(55.0-59.7)$ & \multirow{3}{*}{$<.001$} & 3,513 & $30.3(28.3-32.4)$ & \multirow{4}{*}{$<.001$} \\
\hline $65-74$ & NA & NA & & 1,903 & $44.7(41.8-47.6)$ & \\
\hline $65-75$ & 2,073 & $71.6(69.3-73.9)$ & & NA & NA & \\
\hline$>75$ & $-{ }^{a}$ & $-{ }^{\mathrm{a}}$ & $-{ }^{a}$ & 1,220 & $40.6(36.8-44.4)$ & \\
\hline \multicolumn{7}{|l|}{ Education } \\
\hline Less than high school & 770 & $53.9(48.4-59.3)$ & \multirow{4}{*}{$<.001$} & 1,013 & $26.9(22.8-31.3)$ & \multirow{4}{*}{$<.001$} \\
\hline High school graduate & 1,504 & $58.5(54.7-62.1)$ & & 1,786 & $32.7(29.7-35.9)$ & \\
\hline Some college or associate degree & 1,658 & $60.1(56.9-63.1)$ & & 1,829 & $34.4(31.5-37.5)$ & \\
\hline College graduate & 1,747 & $69.0(65.8-72.0)$ & & 2,008 & $42.3(39.1-45.6)$ & \\
\hline \multicolumn{7}{|c|}{ Annual income, percentage of federal poverty level } \\
\hline$<139 \%$ & 1,076 & $55.2(50.7-59.7)$ & \multirow{4}{*}{.01} & 1,213 & $30.8(26.6-35.4)$ & \multirow{4}{*}{$<.001$} \\
\hline $139 \%-250 \%$ & 1,051 & $59.9(55.5-64.1)$ & & 1,325 & $32.7(29.0-36.7)$ & \\
\hline $251 \%-400 \%$ & 1,091 & $61.0(56.8-65.0)$ & & 1,365 & $32.2(28.9-35.7)$ & \\
\hline$>400 \%$ & 2,461 & $64.9(62.0-67.6)$ & & 2,733 & $39.5(37.1-42.0)$ & \\
\hline \multicolumn{7}{|l|}{ Usual source of health care } \\
\hline $\begin{array}{l}\text { None or hospital emergency } \\
\text { department }\end{array}$ & 589 & $42.2(35.5-49.1)$ & \multirow[t]{2}{*}{$<.001$} & 619 & $20.2(13.7-28.6)$ & \multirow[t]{2}{*}{$<.001$} \\
\hline Has usual source & 5,090 & $63.6(61.7-65.6)$ & & 6,017 & $36.6(34.9-38.4)$ & \\
\hline \multicolumn{7}{|l|}{ Health insurance } \\
\hline Private or military & 3,815 & $63.6(61.4-65.8)$ & \multirow{3}{*}{.003} & 4,387 & $37.3(35.3-39.3)$ & \multirow{3}{*}{.01} \\
\hline Public only ${ }^{\mathrm{c}}$ & 1,456 & $59.4(55.4-63.3)$ & & 1,844 & $32.7(29.6-36.0)$ & \\
\hline Uninsured & 408 & $49.0(40.8-57.2)$ & & 405 & $26.0(17.8-36.2)$ & \\
\hline \multicolumn{7}{|l|}{ Race/ethnicity } \\
\hline Hispanic & 624 & $57.7(51.3-63.8)$ & \multirow{5}{*}{.12} & 713 & $34.3(29.0-40.1)$ & \multirow{5}{*}{$<.001$} \\
\hline Non-Hispanic white & 4,034 & $62.6(60.3-64.8)$ & & 4,786 & $36.9(35.0-38.8)$ & \\
\hline Non-Hispanic black & 716 & $65.5(61.3-69.4)$ & & 790 & $38.3(34.1-42.7)$ & \\
\hline Non-Hispanic Asian & 251 & $51.1(40.9-61.2)$ & & 289 & $16.8(11.6-23.8)$ & \\
\hline Non-Hispanic other ${ }^{d}$ & 54 & $62.9(47.4-76.1)$ & & 58 & $29.1(13.9-50.9)$ & \\
\hline
\end{tabular}

Abbreviations: $\mathrm{Cl}$, confidence interval, NA, not applicable.

${ }^{a}$ Fecal occult blood test (FOBT) in the past year, flexible sigmoidoscopy in past 5 years with FOBT in past 3 years, or colonoscopy in past 10 years. Colorectal cancer screening is not recommended for people older than 75 .

${ }^{b}$ Proportions of screened individuals adjusted for all covariates in table. Values are computed for a specific group (eg, type of health insurance) as the sample weighted average of the predicted responses from the logistic regression model, assigning each individual in the sample to that group membership while keeping all other covariates unchanged. The sample totals for this table are crude estimates of the proportion screened in the total population.

${ }^{\mathrm{c}}$ Medicare and/or Medicaid.

${ }^{\mathrm{d}}$ American Indian, Alaska Native, and Pacific Islander.

The opinions expressed by authors contributing to this journal do not necessarily reflect the opinions of the U.S. Department of Health and Human Services, the Public Health Service, the Centers for Disease Control and Prevention, or the authors' affiliated institutions. 
(continued)

Table 3. Cancer Screening Among Men, by Demographic Characteristics and Access to Care, National Health Interview Survey, United States, 2015

\begin{tabular}{|c|c|c|c|c|c|c|}
\hline \multirow[b]{2}{*}{ Characteristic } & \multicolumn{3}{|c|}{ Colorectal Cancer, Recent Test ${ }^{a}$} & \multicolumn{3}{|c|}{ Prostate Cancer, PSA Test in Past Year } \\
\hline & No. & Predictive Margin $(95 \% \mathrm{Cl})$ & $P$ Value & No. & Predictive Margin $^{\mathrm{b}}(95 \% \mathrm{Cl})$ & $P$ Value \\
\hline$<10$ years & 51 & $52.1(38.4-65.5)$ & \multirow{3}{*}{.33} & 51 & $29.9(17.0-47.2)$ & \multirow{3}{*}{.54} \\
\hline$\geq 10$ years & 783 & $60.4(54.8-65.6)$ & & 907 & $37.8(32.4-43.5)$ & \\
\hline US-born & 4,845 & $62.2(60.1-64.3)$ & & 5,678 & $35.6(33.8-37.4)$ & \\
\hline \multicolumn{7}{|c|}{ Consulted a doctor in past 12 months } \\
\hline Yes & 4,338 & $65.8(63.6-67.9)$ & \multirow{2}{*}{$<.001$} & 5,163 & $39.6(37.8-41.4)$ & \multirow{2}{*}{$<.001$} \\
\hline No & 1,341 & $47.8(44.2-51.5)$ & & 1,473 & $18.3(15.3-21.8)$ & \\
\hline
\end{tabular}

Abbreviations: $\mathrm{Cl}$, confidence interval, NA, not applicable.

${ }^{a}$ Fecal occult blood test (FOBT) in the past year, flexible sigmoidoscopy in past 5 years with FOBT in past 3 years, or colonoscopy in past 10 years. Colorectal cancer screening is not recommended for people older than 75 .

${ }^{\mathrm{b}}$ Proportions of screened individuals adjusted for all covariates in table. Values are computed for a specific group (eg, type of health insurance) as the sample weighted average of the predicted responses from the logistic regression model, assigning each individual in the sample to that group membership while keeping all other covariates unchanged. The sample totals for this table are crude estimates of the proportion screened in the total population.

${ }^{\mathrm{c}}$ Medicare and/or Medicaid.

${ }^{\mathrm{d}}$ American Indian, Alaska Native, and Pacific Islander. 